\title{
EFEITOS DO SOBREAMENTO EM MUDAS DE Cabralea Glaberrima Juss. SOB CONDIÇŌES DE VIVEIRO
}

Odilson dos Santos Oliveira, Juarez Martins Hoppe e Elio Luiz Champa nhol

Departamento de Ciēncias Florestais. Centro de Ciēncias Rurais.UFSM. Santa Maria, RS.

RESUMO

No viveiro do Departamento de Ciências Florestais, da UFSM, Santa Maria-RS, foi analisado o desenvolvimento de mudas de cangera na (Cabralea glaberrima), sob $0,25,50,70$ e $80 \%$ de sombreamento. 0 experimento foi instalado em campānulas de $1,50 \mathrm{~m} \times 1,0 \mathrm{~m} \times 0,70 \mathrm{~m}$ de comprimento, altura e largura, respectivamente, com armação de ferro, cobertas com tela plās tica com diferentes niveis de sombreamento, envolvidas lateralmente com a mesma tela, em trēs repetições e 30 indivĩduos por parcela. Apōs 12 meses foram avalia das suas alturas finais, diāmetro de colo e produção de matēria seca, quando foi observado uma altura estatisticamente superior em mudas sob $70 \%$ e $80 \%$ de som breamento. Iguais resultados foram obtidos para a produção de matéria seca total nos referidos nĩveis, influenciada por uma maior produção de matéria seca da par te aérea, sigificativamente superior aos demais tratamentos. Para o diāmetro de colo, não houve diferença significativa entre os tratamentos.

SUMMARY

OLIVEIRA, O. dos S.; HOPPE, J.M. and CHAMPANHOL, E.L., 1990. Effects of shading on yield of Cabralea glaberrima Juss. under con ditions of nursery. Ciência e Natura 11: 113-117, 1989

In the nursery at the Department of Science Foresty, of the UFSM, the development of seedlings of cangerana icabralea gla berrima) was analysed with $0,25,50,70$ and 80 percent of shade. The experiment was set under iron bell-glass and web plastic. After a period of 12 months results were obtained of the height of see dlings in 70 and $80 \%$ of shade levels statistically greater than for the rest of treatment. The production of dry matter also was statis tically greater being influenced by a larger production of dry matter of the aerial part. Regarding the collor diameter no signifi cant difference was found.

INTRODUÇÃO

Face a necessidade do enriquecimento das florestas nativas e principalmente a conservação de potenciais genéticos, pesquisado res vem buscando dados, através de pesquisas, sobre as exigências dessas espécies, colecionando informações importantes sobre sua a toecologia. 
Experiēncias tem mostrado que muitas essências autoctones não apresentam bom desenvolvimento e adaptação quando utilizados plan tios em plena luz, carecendo de informações de ambientes prōprios onde, dentre outros fatores, o controle de luminosidade faz-se con dição bāsica, para sua melhor produtividade. Assim, face as dificul dades e elevados custos nos trabalhos de experimentação a campo pa ra obtenção dessas informações, são justificáveis pesquisas a nĩvel de viveiro para a coleta de subsidios que possam levar grandes suces sos à implantação de povoamentos a nível comercial, face suas indis cutīveis qualidades.

RE $\forall I S A ̃ O ~ B I B L I O G R \bar{A} F I C A$

Pouca atenção tem sido dado ao conhecimento das necessida des ecológicas das espēcies nativas. Condições do meio ambiente, so bretudo o fator luz, são importantes para o desenvolvimento e sobre vivência das mesmas.

0 sombreamento de algumas espécies resulta numa resposta positiva ao crescimento em altura e diâmetro de colo (JESUS et alli e FERREIRA et alli ${ }^{3}$ ). Já para outras espécies, a luminosidade se tor na condição bāsica para o seu desenvolvimento (ALENCAR \& ARAOJO'). outras espécies reagem de forma indiferente ao fator luz (OLIVEIRA ${ }^{8}$ e ANDRE $^{2}$ ).

FERREIRA et al1 $i^{3}$, trabalhando com quatro espécies flores tais sob diferentes graus de sombreamento, verificaram que para Enterolobium contortisiziquum, as maiores taxas em altura e diâmetro de colo foram obtidas quando com $70 \%$ de sombreamento, o que jā não ocorreu de forma significativa entre os tratamentos para Schizolibium parahyba, Hymenaea stilgocarpa e Pelthophorum dubium. Para Pinus insularis, FERREIRA et a $11 i^{5}$ obtiveram igualmente melhores resulta dos em altura quando com sombreamento de 70\%, jā para diāmetro de colo e produção de matēria seca, os resultados foram maiores em plan tas não sombreadas. Resultados semelhantes foram obtidos por JESUS et a $11 i^{7}$ para Cordia trichotoma quando com $50 \%$ de sombreamento.

Para Eucalyptus grandis, FONSECA et alli $i^{6}$ obtiveram os me 1hores resultados com nîveis de sombreamento entre $25 \%$ e $50 \%$. Já Go MES et alli $i^{5}$, trabalhando com a mesma espécie, obtiveram maiores a $\underline{1}$ turas, produção de matēria seca e diâmetro de colo quando sem som breamento. Semelhantes resultados foram obtidos por STURION \& IEDE ${ }^{9}$, com ocotea porosa, sob três níveis de sombreamento, após 10 meses de observações, melhor desenvolvimento diamétrico e produção de ma tēria seca a céu aberto, porém com menor percentagem de sobrevivēn cia e altura inferior, quando comparado com $30 \%$ de sombreamento.

Analisando o comportamento de Carapa guainensis sob três nīveis de sombreamento a campo, OLIVEIRA ${ }^{8}$ não observou diferenças significativas em altura entre os tratamentos, concluindo tratar-se 
de espēcie de fäcil adaptação à diferentes intensidades de luz. En tretanto, ALENCAR \& ARAOJO ${ }^{1}$, trabalhando com espécies florestais na região amazónica, observaram que a sobrevivência e o crescimento de vārias espēcies eram sensivelmente afetados pelas diferentes inten sidades de luz.

\section{MATERIAIS E METODOS}

0 ensaio foi instalado nas dependēncias do Departamento de Ciências Florestais, da Universidade Federal de Santa Maria, no pe ríodo de agosto/89 a agosto/90.

As mudas foram produzidas por semeadura direta em sacos de polietileno de $12 \mathrm{~cm}$ de diāmetro por $25 \mathrm{~cm}$ de altura, utilizando-se como substrato, solo de viveiro, construỉdo de terra de campo e com posto orgânico, na proporção de $3: 1$, dispostas no sentido Norte-Sul.

0 experimento foi instalado num delineamento.inteiramente casualizado, com cinco tratamentos, três repetições e trinta plantas por parcela. Os nỉveis de sombreamento utilizados, foram 25, 50, 70 e $80 \%$ obtidos por meio de telas de polielefinas de cor preta e $0 \%$ ao aberto, cobrindo as porções superiores e laterais das mudas em campānulas com armação de ferro, nas dimensões de $1,50 \mathrm{~m} \times 1,0 \mathrm{~m} \times$ $0,70 \mathrm{~m}$, de comprimento, altura e largura, respectivamente.

Para evitar concorrência de sombra com ervas daninhas, efe tuou-se a limpeza das mudas sempre que necessário.

Mensalmente, eram avaliadas suas alturas e diámetro de co 10, com avaliação do peso de matēria seca após a última medição. 0 peso de matēria seca foi obtido atravēs do peso seco em estufa com ventilação forçada a $75^{\circ} \mathrm{C}$, por 48 horas.

Com os dados coletados, procedeu-se a análise de variância para altura, diâmetro de colo, peso das razíses, parte aérea e peso total. Para comparação das médias, utilizou-se o teste Tukey, ao nível de $1 \%$ Je probabilidade.

\section{RESULTADOS E DISCUSSÃO}

Os níveis de sombreamento mostraram diferenças no compor tamento entre os parâmetros analisados. A altura foi significativa mente influenciada, onde o melhor crescimento foi verificado em mu das com $70 \%$ e $80 \%$ de sombreamento. Já no caso do diâmetro de colo, os tratamentos não mostraram qualquer diferença significativa (Tabe la I). Quando sob plena luż, as mudas, alēm de apresentarem crescí mento reduzido e irregular, o indice de sobrevivência era menor.

A produção de matēria seca total, em função das diferentes intensidades luminosas, foi significativamente maior em mudas com som breamento de $70 \%$ e $80 \%$ em relação aos demais nỉveis. Com relação a produção de matēria seca da parte aérea, observou-se maiores incre mentos em mudas sombreadas e que a produção de matéria seca total 
foi grandemente influenciada pela produção de matéria seca da parte aérea em relação às de menor sombreamento.

TABELA I - MEDIAS DAS ALTURAS E DIĀMETRO DE COLO SOB DIFERENTES NI VEIS DE SOMBREAMENTO.

\begin{tabular}{ccc}
\hline \hline $\begin{array}{c}\text { Nível de sombreamento } \\
(\%)\end{array}$ & $\begin{array}{c}\text { Altura } \\
(\mathrm{cm})\end{array}$ & $\begin{array}{c}\text { Diâmetro de colo } \\
(\mathrm{mm})\end{array}$ \\
\hline 0 & $13,7 \mathrm{a}$ & $8,3 \mathrm{a}$ \\
25 & $16,4 \mathrm{a}$ & $7,4 \mathrm{a}$ \\
50 & $20,6 \mathrm{~b}$ & $7,7 \mathrm{a}$ \\
70 & $26,6 \mathrm{c}$ & $8,9 \mathrm{a}$ \\
80 & $31,7 \mathrm{~d}$ & $8,8 \mathrm{a}$ \\
\hline
\end{tabular}

Obs.: Mēdias seguidas da mesma letra, não diferem estatisticamente entre si, ao nível de $1 \%$ de probabilidade, pelo teste Tukey.

Embora a produção de matéria seca da parte aérea e parte radicular não tenha mostrado diferenças significativas entre os tra tamentos, observou-se uma nitida superioridade dos tratamentos com níveis de $50 \%, 70 \%$ e $80 \%$ de sombreamento em relação ao's de menorsom breamento e que as mudas sob plena luz, apresentaram elevado indice de bifurcações.

0 aumento da produção de matéria seca provocado pelo maior nível de sombreamento pode ser explicado por um baixo ponto de com pensação luminosa da espécie em virtude de sua tolerância à sombra, fato este comprovado em mata natural.

TABELA II - MEDIAS DE PRODUÇAO DE MATERIA SECA TOTAL, PARTE AEREA E PARTE RADICULAR, EM DIFERENTES NIVEIS DE SOMBREAMENTO.

\begin{tabular}{cccc}
\hline $\begin{array}{c}\text { Nível de sombreamento } \\
(\%)\end{array}$ & $\begin{array}{c}\text { Total } \\
(\mathrm{gr} .)\end{array}$ & $\begin{array}{c}\text { P. Aérea } \\
(\mathrm{gr} .)\end{array}$ & $\begin{array}{c}\text { P. radicul r } \\
(\mathrm{gr} .)\end{array}$ \\
\hline 0 & $4,7 \mathrm{a}$ & $1,8 \mathrm{a}$ & $3,0 \mathrm{a}$ \\
25 & $4,8 \mathrm{a}$ & $1,3 \mathrm{a}$ & $2,4 \mathrm{a}$ \\
50 & $7,6 \mathrm{a}$ & $4,0 \mathrm{a}$ & $4,6 \mathrm{a}$ \\
70 & $12,6 \mathrm{~b}$ & $8,0 \mathrm{a}$ & $6,3 \mathrm{a}$ \\
80 & $16,2 \mathrm{~b}$ & $6,6 \mathrm{a}$ & $5,1 \mathrm{a}$ \\
\hline
\end{tabular}

Obs.: Médias, seguidas da mesma letra, não diferem estatisticamente entre si, ao nível de $1 \%$ de probabilidade, pelo teste Tukey.

CONCLUSOES

1) A altura das mudas foi influenciada significativamente pelos di ferentes niveis de sombreamento, onde $70 \%$ e $80 \%$ proporcionaram melhor desenvolvimento, diferindo dos demais.

2) o diâmetro de colo não foi influenciado pelos tratamento. 
3) 0 peso de matēria seca total foi significativamente maior em mu das com maior sombreamento, influenciada por uma maior produção de matéria seca da parte aērea.

4) A produção de matéria seca da parte aérea e parte radicular de forma isolada, estatisticamente, não foram influenciadas pelos tratamentos, embora tenha sido observado uma nitida superiorida de dos tratamentos $50 \%, 70 \%$ e $80 \%$, em relação aos demais para a parte aérea.

\section{LITERATURA CITADA}

1. Alencar, J.C. \& ARAOjo, V.C. Comportamento de Espécies Florestais Amazōnicas quanto a Luminosidade. Manaus. Acta Amazōnica, 10 (3): 435-444. 1980 .

2. ANDRAE, F.H. Ecologia Florestal. Santa Maria. U.F.S.M. Departa mento de Ciēncias Florestais. 1978. $228 \mathrm{p}$.

3. FERreira, M.G.; CĀNDIDO, J.F.; CANO, N.A.0. \& CONDE, A.R. Efeito do Sombreamento da Produção de Mudas de Quatro Espécies Flo restais Nativas. Viçosa. REV. ARVORE. V.1 (2) 121-134. 1977.

4. FERREIRA, M.G.; CĀNdido, J.F.; Silva, D.A. \& COLODETTE, J.L. Efei to do Sombreamento e da Densidade de Sementes sobre o Desen volvimento de Mudas de Pinus insularis Endlicher e seu Cresci mento Inicial no campo. Curitiba. REV. FLORESTA, 12 (1):56-61. 1981.

5. GOMES, S.M.; FERREIRA, M.G.M.; BRANDi, R.M. \& NETO, F.P. Influên cia do Sombreamento no Desenvolvimento de Eucaliptus grandis W. Hill ex Maiden. Viçosa. REV. ArVORE, V.2 (1):68-75. 1978.

6. FONSECA, A.G.; BRANDI, R.M.; PAULA NETO, F. \& CANDIDO, J.F. Efe to do Sombreamento, Tamanho e Peso de Sementes na Produção de Mudas de $E$. grandis W. Hill ex Maiden e no seu Crescimento Ini cial no Campo. Viçosa. ReV. ARVORE, V.3(2):145-149. 1979.

7. JESUS, R.M.; LOGISTER, F. \& MENANDRO, M.S. Efeito da Luminosida de e do Substrato na Produção de Mudas de Cordiatrichotoma (VE11) Arrab. In: VI CONGRESSO FLORESTAL ESTADUAL, V. 1. Nova Prata. 1988. p:459-469.

8 OLIVEIRA, 0.S. A andiroba (Carapa guianensis) e seu Comportamento Silvicultural em Diferentes Intensidades de Luz. In: I CONGRES SO BRASILEIRO DE FLORESTAS TROPICAIS. Viçosa. Universidade Fe deral de Viçosa. 1974. p:579-590.

9. STURION, J.A. \& IEDE, E.D. Influência da Profundidade de Semeaduu ra, Cobertura de Canteiros e Sombreamento na Formação de Mudas de ocotea porosa (Ness) Barroso. Documentos. EMBREPA/URPFCS. Curitiba. Nọ 10. 1982. p:71-79.

Recebido em outubro, 1990; aceito em novembro, 1990. 
